\title{
General and 'Neighbourly' Trust in Border Regions: An Analysis of the Influence of Disintegration Experience and of Self-Enhancement Mentalities in the German-Czech Border Regions*
}

\author{
KLAUS BOEHNKE** \\ Jacobs University Bremen \\ SUSANNE RIPPL \\ Technische Universität Chemnitz
}

\begin{abstract}
This article examines the question of appropriate individual-level predictors of generalised and 'neighbourly' cross-border trust in a general population survey in the adjacent border regions of Germany and the Czech Republic $(N=1129)$. It studies the impact of perceived economic, political, and spatial disintegration (as defined by Heitmeyer) and of self-enhancement mentalities (hierarchic self-interest, xenophobia) on generalised and particular, in this case 'neighbourly' cross-border trust, as well as the interrelation of the two types of trust. In line with earlier studies in the field, it emerged that, although being significant predictors of trust, neither perceived disintegration nor self-enhancement mentalities predict generalised trust well. Less than $5 \%$ of the variance was explained. In conjunction with contextual predictors (contact density and historic narratives), generalised trust, however, was a very good predictor of cross-border trust.
\end{abstract}

Keywords: trust, disintegration, self-enhancement, German-Czech border region

Sociologický časopis/Czech Sociological Review, 2012, Vol. 48, No. 6: 1075-1092

Many sociologists consider trust an important source of human behaviour in individual (interpersonal trust) and group (social trust) relationships [Luhmann 1988; Gambetta 1988; Coleman 1990; Putnam 1993; Hollis 1998; Portes 1998; Delhey and Newton 2003]. Putnam regards trust as the central component of social capital, laying the foundation for the integration and togetherness of a community. Controversial discussions about the meaning of the individual versus social conditions of trust-building and about the relevance of individual factors [Putnam 2000;

\footnotetext{
* This article is based on research funded by the Deutsche Forschungsgemeinschaft (DFG) in grants to the first (Bo 929/20-1) and the second author (Ri 858/7-1).

** Direct all correspondence to Klaus Boehnke, Bremen International Graduate School of Social Sciences (BIGSSS), Jacobs University Bremen, Campus Ring 1, D-28759 Bremen, Germany, e-mail: K.Boehnke@jacobs-university.de.
} 
Uslaner 2002] characterise the debates on how trust develops. Approaches that focus on the individual actor consider trust as a quasi-personality trait, which is acquired in early childhood through socialisation [Uslaner 2002]. Other authors emphasise the strong contextual determination of trust. Hardin [1993] assumes that trust acquired through socialisation is constantly modified by changing living conditions. Society-oriented theories of trust consider the social context or more specifically the general social conditions in which we live (such as the efficiency of institutions or the vitality of social networks) as decisive factors for the development of social trust [Knack and Keefer 1997; Putnam 2000; Inglehart and Welzel 2005; Delhey and Newton 2005]. To date empirical studies have not yet resolved the controversy about the role of different influence factors. However, it has become apparent that there are hardly any strong predictors of general social trust at the individual level. Newton [2006: 353] even concludes that 'in sum, social and political trust when viewed from the individual level is a puzzle'.

The present study tries to offer further clues for solving the puzzle of the multiple roots of different forms of trust. We will focus our analyses on the following questions: How do individuals' experience of integration and disintegration and their attitudes and value orientations respectively (if at all) influence general and particular social trust? And in what way does general social trust impact specific forms of trust in particular social groups? It is in this context that the occurrence of a particular form of trust, here 'transnational trust in border regions', will be examined. It will be assumed that the general social trust of people determines the strength of particular forms of trust, while the basic (living) conditions in the border region modify the particular, individual willingness to trust, but not in the first place the level of general trust.

\section{Theoretical considerations}

This study aims at analysing the interplay of a subjective disintegration experience and of individual attitudes and value orientations with the occurrence of different forms of social trust. Our particular focus is on 'neighbourly trust' in the German-Czech border region. In our definition of social trust, we follow Newton [2006: 343], who terms social trust 'as the belief that others will not deliberately or knowingly do us harm, if they can avoid it, and will look after our interests, if this is possible'. We will examine general social trust, which-in contrast to particular trust-is not bound to concrete face-to-face interaction, but rather represents a sort of abstract trust in others. This kind of trust is especially important for integration and stability in modern, spacious, and geographically mobile societies [Newton 2006: 345]. Consequently, this study will first deal with general trust in people as such, so-to-speak, in a broader context, but it will secondly also address trust at a 'lower level' of the public (particular trust in people from the neighbouring country of the border area under scrutiny). The development of particular forms of trust we presume to be influenced by contextual factors to a much greater extent. 


\section{Modernisation and trust}

In analyses of trust, lines of argumentation connecting it to modernisation theories can already be found in the sociological classics by Tönnies [(1887) 2005] and Simmel [(1902) 1992]. Modernisation can roughly be defined as a complex process of interconnected changes in different social spheres like the economy, culture, social life, and politics, encompassing processes of differentiation, rationalisation, and individualisation [for an overview, see Harris 1992]. In the sphere of social relations the process of individualisation becomes an important feature. The individual is increasingly liberated from strong social bonds in homogeneous traditional settings, only to develop more and more into the individual builder of his or her own identity. Increasing freedom is simultaneously accompanied by a loss of embeddedness in social groups. In this logic, modernisation processes alienate people from collective entities and thereby reduce trust. More recent individualisation theory [Beck 1986; Giddens 1990] describes the dissolution of traditional and social bonds and the related loss of security and reliable norms as ambivalent processes of liberation, as well as disintegration. In contemporary academic discourse, Putnam [2000], in particular, emphasises the idea that modernisation and the implied individualisation result in a decrease of social trust, thereby endangering the cohesion of society as a whole [see also, Putnam 1993].

Newton [2006] and Zmerli [2008] point out that the existing empirical evidence for these assumptions is heterogeneous. Even Putnam himself was unable to find convincing empirical support for his theories [1995, 2000]. The results of an international comparison are indeed divergent [Gabriel et al. 2002]. In general, wealthy and developed societies - which are the most modernised societies ${ }^{1}$ are the ones that 'possess' the highest level of social trust [Inglehart 1997; Delhey, Newton and Welzel 2011]. What we are ultimately dealing with is a debate over modernisation theories. Earlier approaches that focused on a similar, linear way of development in multiple spheres of society and tended to see one quasiteleologically defined path of modernisation are now being contrasted with approaches that prefer the idea of multiple modernities [e.g. Eisenstadt 2000]. The commonalities of the perceived multiple modernities might even be very small. Some theorists see the human effort for 'active Weltbeherrschung', in the Weberian sense, and a reflective attitude-that makes a single binding worldview impossible-as the least common denominator of the current era [Schwinn 2006]. At the same time, the work of Inglehart in particular has revealed the strong connection between economic development and the wealth of a nation on the one hand and the formation of certain cultural orientations emphasising secularity and the individual self-actualisation of people on the other.

The interrelation between modernisation and trust can be examined more closely on the micro level. Various such studies have shown that modernisation affects people in different ways, depending on the degree of integration into modern society that the individual achieves. Integration can be understood as 
reflecting possibilities of participation, for example, in politics or the economy. Not surprisingly, 'modernisation winners', in the sense of accomplished integration, tend to be those with the highest degree of social trust. A sufficiently high level of income is often taken as a proxy for successful economic integration accompanied by a high degree of self-contentment, which is likely to come with high levels of social trust in different cultural contexts [Newton 1999; Whiteley 1999; Putnam 2000; Paxton 2002]. People who individually profit from modernisation-in the sense of participation and integration-show a higher degree of trust than the 'losers' in this process. This division of society can cause a loss of trust at the macro level. Inglehart [1999], Knack and Keefer [1997], and Delhey and Newton [2005] illustrate that inhomogeneous, strongly polarised societies with a selective welfare system show a lower level of trust compared to societies that experience less social division.

These results can be interpreted against the background of the disintegration theory proposed by Heitmeyer and his colleagues [1997; Heitmeyer and Anhut 2008]. They argue that the process of individualisation-accelerated by modernisation-leads to an increasing level of disorientation in society on a dayto-day basis. The pressure of an increasingly competitive mentality, mobility and flexibility, accompanied by a loss of stability and security in social relations and in the labour market lead to increasing levels of Mertonian anomia, or, in Heitmeyer's words, a disintegration experience. Successful social integration within a society is rewarded with a high social status and high income but-as Heitmeyer sees it-such a status has been becoming increasingly insecure and temporary. This situation generates decreasing trust in the community, its members, and its institutions, which form the framework for a 'successful' way of life. Social disintegration - characterised by the experience of low income and a low social status - is a state of being insufficiently recognised by the community, which leads to feelings of relative deprivation. It is this relativistic framing in particular that emphasises the fact that feelings of deprivation are bound to a community and are not idiosyncratic individual emotions. What a person feels is not a mere internal sentiment, but has its roots in the person's perceived position in a social entity. Accordingly, insufficient recognition by the community is accompanied by a decreasing degree of social trust, which in extreme cases evolves into anomia.

In addition to the effects of socio-economic integration and disintegration on the development of social trust, other aspects of disintegration can also be presumed to have a negative impact on the formation of social trust. It seems likely that a feeling of insufficient political efficacy also results in the sense that the community and its institutions are untrustworthy. Furthermore, the social mobility that characterises modern societies and the implied lack of 'spatially located' integration is also likely to influence individuals' feelings of solidarity towards the community. A high degree of spatial mobility reduces the development and experience of belongingness to a regional unit. This proposition is in the broadest sense based on the network-theory assumptions of Putnam, who ascribed a great 
confidence-building effect to the density of interactions that develop out of continuity. The dissolution of regional and social milieus caused by increased mobility can thus be assumed to countervail the formation of trust in networks.

Over and above socio-economic deprivation, political inefficacy, and increasing spatial mobility, which-according to Heitmeyer-represent the concomitant phenomena of an individualised society, one can more often than not find a specific pattern of mentalities in individualised market economies. Such capitalist mentalities [Boehnke and Dragolov forthcoming] place special emphasis on the individual and his/her interests. Individualism, competition, and the implied success of the individual are central themes of market economies; Hagan, et al. [1999] speak of 'hierarchic self-interest' (HSI). These attitude and value patterns that revolve around the self-enhancing, competitive individual conflict with the idea of a solidly united society with high levels of interpersonal trust [Putnam 2000]. When individuals are ever more rarely integrated into solidly united relations, self-enhancement mentalities (with the foci on individual benefits and competition) gain in importance as action criteria. Putnam [2000] uses the term 'bowling alone' to describe the increasing atomisation of society and accompanying decrease in general social trust.

Often such orientations are accompanied by an other-derogation outlook [Schiefer et al. 2010]. Non-members of the ingroup are seen as a threat to one's identity. Such an outlook need not, however, necessarily lead to weaker generalised trust [Macy and Skvoretz 1998]. Other-derogatory attitudes are only in part attitudes directed against any outgroup, but at least to some extent they tend to have a specific target. It is, thus, likely that such attitudes more sizably affect trust in specific groups than general trust.

\section{The German-Czech border regions}

Border regions can be seen as a test tube or laboratory for processes that also hold significance for broader integration processes in Europe. The predictor variables under observation to varying extent characterise these regions. On the one hand, border regions are peripheral with regard to their economic and cultural situation. This is especially true for the regions on the borders of the East European states that used to be situated along the edge of the Iron Curtain. The unemployment rate in these border regions tends to be higher than in more central regions of the given countries and average income tends to be lower [Niebuhr 2008]. They also experience high levels of out-migration of the younger population [Rippl et al. 2010]. These factors serve to intensify feelings of disintegration on both sides of the state border in these regions. On the other hand, they may also be seen as laying the ground for certain feelings of communality or a 'similar fate' on both sides of the border. In the German-Czech case, however, potential feelings of communality are likely thwarted by the region's very conflict-laden shared his- 
tory. In sum, our analysis is focused on a distinct setting with (specific) contextual features that could impede or enhance processes of trust building. We assume that the specific context of the region (its history and direct contact experience) primarily affects the particular 'neighbourly' trust between Czechs and Germans, not the level of generalised trust. At the same time, the stronger disintegration experience in the regions cannot be blamed on the neighbour group, and should, thus, have more to do with the general level of social trust.

\section{Hypotheses}

Based on the argumentation elaborated above, we assume that with increasing modernisation and individualisation the degree of general social trust and subsequently particular 'neighbourly' trust declines in society. At the micro level, the presumed mechanisms can be formulated into the following empirically testable hypotheses:

H1: Disintegration experience reduces general social trust. H1a: Economic disintegration experience reduces general social trust. H1b: Political disintegration experience reduces general social trust. H1c: Spatial disintegration experience reduces general social trust.

H2: Self-enhancement and outgroup-derogatory mentalities reduce trust.

H2a: Hierarchically self-interested value orientations reduce general social trust.

H2b: Xenophobic attitudes reduce particular ('neighbourly') and general social trust.

H3: General social trust is the most important predictor for group-specific particular social trust.

H4: Group-specific particular but not general social trust is impacted by the specificities of the relationship situation between specific groups in border regions.

We set out to test these hypotheses in a comprehensive structural equation model, where three aspects of disintegration serve as the primary predictors of both types of trust, the two attitudinal constructs (HSI and xenophobia) serve as additional predictors of trust, independently and as mediators of disintegration, and the specificities of the trans-border context under scrutiny only predict 'neighbourly' trust. We do not separately work through the hypotheses one by one, but in a comprehensive model. The model is documented in the results section. 


\section{Data and measures}

\section{Samples}

The data analysed here were collected in November and December 2006 within a fifty-kilometre-wide strip of territory in the adjacent German and Czech border regions on both sides of the border using standardised interviews on a population sampled via random probability sampling. The interviews in the German border regions were conducted via telephone; a random digit dialling sampling procedure was employed among the landline telephone numbers in the defined region, supplemented by the well-known 'last birthday' method in case several persons were reachable under a selected telephone number. The interviews in the Czech border regions were conducted face-to-face, since the landline phone density there was assessed as limited at the time. Addresses were selected at random from an existing list of addresses in the selected area; supplemented once again by a last birthday selection if an address led to multiple individuals. Only German (in Germany) and Czech citizens (in the Czech Republic) aged 14 and older were interviewed. The general population survey was supplemented by an oversampling in cities located close to the border. More specifically, four pairs of towns were selected per region, which in terms of their distance from each other and from the border are relatively easily reachable for their respective neighbours. In the urban subsample, persons living in Karlovy Vary, Děčín, Cheb, and Domažlice were interviewed on the Czech side. The urban German samples came from the towns of Annaberg-Buchholz, Pirna, Marktredwitz and Furth im Wald. Respondents in the respective towns were also chosen via the above-described random probability sampling procedure by a professional agency (IM Leipzig). ${ }^{1}$ In addition to the two general-population border-region samples, about 75 people per town were interviewed. In total, sample sizes of $N=602$ in the German-Czech border region and $N=527$ persons in the Czech-German border region were created. Our samples can thus be seen as regionally representative, with an oversampling of the urban population segment. A comparison of important demographic variables (age, gender, and education) of the samples and the population supports this. We found a slightly higher educational level in our samples than in the population data available from European Union NUTS (Nomenclature of Territorial Units for Statistics) reports. ${ }^{2}$ Whether this reflects the oversampling of urban participants or whether this is due to a slightly greater willingness of more highly educated people to respond positively to an interview request, is difficult to determine, because available statistics do not fully match our population definition of residents in a fifty-kilometre-wide strip on both sides of the border.

\footnotetext{
${ }^{1}$ http://www.imleipzig.de/pages_e/full_service.html.

${ }^{2}$ http://appsso.eurostat.ec.europa.eu/nui/show.do?dataset=edat_lfse_11\&lang=en.
} 


\section{Measures}

General social trust was evaluated by what is likely to be the standard item of trust research, already used in diverse surveys such as the International Social Survey Programme (ISSP) ${ }^{3}$ or the European Values Study (EVS). ${ }^{4}$ Respondents were directly asked to what extent they trust people in general. Additionally, an item was added which measured 'trust in people from the neighbouring country' in the Czech-German border region. ${ }^{5}$ Even though the formulation of the trust item in the two variants is not without controversy, it has shown its reliability and discriminant validity in a multitude of studies [Newton 2006].

To measure subjectively-felt economic and political disintegration, again items from established instruments were used. Economic disintegration was measured by the pertinent item from ALLBUS, the German General Social Survey. ${ }^{6}$ Respondents were asked to what extent they believed that they were getting a fair share of the general welfare in comparison to others. ${ }^{7}$ Political disintegration was measured by means of two items that assess perceived political powerlessness: 'People like me anyway do not have an influence on the actions of the government' and 'I think it is pointless to get involved politically'. The two-item scale had a consistency of $\alpha=.71$ in the overall sample, with country-specific alphas at $\alpha=.70$ in Germany and $\alpha=.71$ in the Czech Republic. Spatial disintegration was measured as the duration the respondent has lived in the region-as a proxy. To assess disintegration, years of residence were inverted and multiplied by 100 (100/years of residence) to simultaneously achieve a central tendency of empirical scores that is not too different from the central tendencies of the other two disintegration measures.

To assess self-enhancement mentalities, a second-order scale score for hierarchic self-interest (HSI) was calculated [Hagan et al. 1999; Hadjar 2004]. Using two items each, the HSI comprises four first-order constructs (individualism: 'We would all be better off if everyone simply cared for him/herself' and 'In order to excel, one must be able to stand alone'; materialism: 'Without achievement there is no happiness' and 'The most important thing in life is achievement'; Machiavellianism: 'It is not important how you win but that you win' and 'One should judge people's deeds based on their success'; and a social comparison orientation: 'It is always my ambition to be better than the average' and 'I would like to

\footnotetext{
${ }^{3}$ http://www.issp.org.

${ }^{4}$ http://www.europeanvaluesstudy.eu.

5 The exact wording of the items: 'Subsequently we are concerned with trust. I will name different groups of people and would like to know whether you have "very much trust", "quite some trust", "little trust", or "no trust at all in them": "people in general", "people from Germany/the Czech Republic".'

${ }^{6}$ http://www.gesis.org/en/allbus.

7 The exact wording of the item: 'In comparison to others who live in Germany/the Czech Republic, how much do you believe you receive? "More than a fair share", "a fair share", "less than a fair share", "much less than a fair share".'
} 
be among the best in all areas of life (job, sports, etc.)'. Consistencies for the four two-item first-order scales varied between $\alpha=.58$ and $\alpha=.65$ in the overall sample, with country-specific alphas varying between $\alpha=.50$ and $\alpha=.66$ in Germany and $\alpha=.60$ and $\alpha=.69$ in the Czech Republic. The alpha of the second-order scale (composed of the four mean scores of the first-order scales) was $\alpha=.62$ in the overall sample, with $\alpha=.59$ in Germany, and $\alpha=.69$ in the Czech Republic. ${ }^{8}$

To measure other-derogatory attitudes (xenophobia), we included two items that originally came from a study by Liebhart and Liebhart [1971]: 'I would have a problem moving to a region where many foreigners live' and 'I rather try to keep away from foreigners'. The consistency of this short scale was $\alpha=.77$ in the overall sample, and $\alpha=.72$ and $\alpha=.82$ in Germany and the Czech Republic, respectively.

As variables meant to accurately explain the specific context of the region, we furthermore included the 'density of contact' between German/Czech neighbours ('How often did you have personal contact with people from the Czech Republic/Germany last year?'). The item had to be answered on a five-point frequency scale ranging from 'never' to 'very often'. The subjective salience of historical conflicts for the current life of respondents was assessed by requesting a rating on a five-point scale (ranging from 'not at all' to 'very strongly') for the item 'The relationship between Germans and Czechs has not always been easy in the past. To what extent do such events as the German occupation of Czech territory before and during the Second World War or the expulsion of Germans from the Sudeten area still today affect your personal relationship with Germans/Czechs?'

\section{Disintegration and trust in the German-Czech border regions}

To allow a first overview of the results, the means and standard deviations of all the included variables are documented for both the Czech and the German subsample.

Table 1 shows that there are quite a number of significant differences in the ratings observed for the Czech and the German side of the border. Economic and political disintegration, xenophobia, the salience of historical conflicts, and general social trust were higher among Czech participants, spatial disintegration and density of contact were higher among German participants, whereas no significant differences were found for the remaining two variables, hierarchic self-interest and trust in one's neighbour. The scores documented in Table 1 sug-

\footnotetext{
${ }^{8}$ Readers should note that although these coefficients appear to be low at first glance, they are indeed more than sufficient for two-item (or, for the second-order scale, four-item) measures. If one were to increase the item number of the measures to, say, eight per scale and calculate the expected consistency of these longer scales by utilising the SpearmanBrown formula, the scales would have consistencies between $\alpha=.80$ and $\alpha=.90$.
} 
Table 1. Means and standard deviations of all included variables

\begin{tabular}{|c|c|c|c|c|}
\hline \multirow[t]{2}{*}{ Variable } & \multicolumn{2}{|c|}{$\begin{array}{c}\text { German } \\
\text { border region }\end{array}$} & \multicolumn{2}{|c|}{$\begin{array}{l}\text { Czech } \\
\text { border region }\end{array}$} \\
\hline & Mean & St. Dev. & Mean & St. Dev. \\
\hline Economic disintegration $^{a}$ & $2.5^{*}$ & 0.7 & 2.6 & 0.7 \\
\hline Political disintegration ${ }^{\mathrm{a}}$ & $2.7^{*}$ & 0.9 & 3.1 & 0.8 \\
\hline Spatial disintegration ${ }^{\mathrm{b}}$ & $5.9^{*}$ & 13.3 & 3.9 & 5.3 \\
\hline Xenophobia $^{a}$ & $2.1^{*}$ & 0.8 & 2.3 & 0.9 \\
\hline Hierarchic self-interest ${ }^{a}$ & 2.3 & 0.5 & 2.3 & 0.6 \\
\hline Density of contact ${ }^{c}$ & $2.9^{*}$ & 1.4 & 2.5 & 1.3 \\
\hline Salience of historical conflicts ${ }^{c}$ & $1.8^{*}$ & 1.1 & 2.4 & 1.2 \\
\hline General social trust ${ }^{a}$ & $3.5^{*}$ & 0.7 & 3.7 & 0.7 \\
\hline Trust in cross-border neighbours ${ }^{\mathrm{a}}$ & 3.3 & 0.7 & 3.4 & 0.8 \\
\hline
\end{tabular}

Source: Authors.

* significant $t$-test, $p<.05$.

a the range of $1-4$ high scores signify high intensity; ${ }^{\mathrm{b}} 100$ divided by the number of regional residence years; ${ }^{c}$ the range of $1-5$ high scores signify high frequency.

gest that levels of trust are quite high in the German-Czech border regions: with means above 3.3 they exceed the scale's expected score of 2.5 by more than one standard deviation.

Subsequently, a comparative analysis of the interrelation of disintegration and trust in both border regions is presented that simultaneously tests our hypotheses. The analysis was conducted in the framework of structural equation models, enabling us to probe sequential, quasi-causal hypotheses. Utilising AMOS19 [Arbuckle 2010], a stacked model was tested using the multi-sample approach, which simultaneously addresses interrelations in both the Czech and the German sample, enabling a systematic comparison of differences between both subsamples. Starting point was the specification of equal parameters in both samples. Parameters were freed on the basis of $\chi^{2}$-difference tests (Wald tests). The models in Figures $1 \mathrm{a}$ and $1 \mathrm{~b}$ show the results of this procedure. Reported are all-standardised-path coefficients that were significant in at least one of the two samples $(p \leq .05)$; paths insignificant in both subsamples obviously are not reported in the figures. ${ }^{9}$ Fit coefficients for the model are excellent: $\chi^{2}=56.780$, $d f=43, p=.078, \chi^{2} / \mathrm{df}=1.320$, IFI $=.980, T L I=.955$, RMSEA $=.017$.

${ }_{9}$ In stacked models, AMOS standardises path coefficients within samples. This usually leads to minutely different coefficients even in instances, where-unstandardised-coefficients were specified to be equal in the two samples. 
Figure 1a. Prediction of trust in the German border region

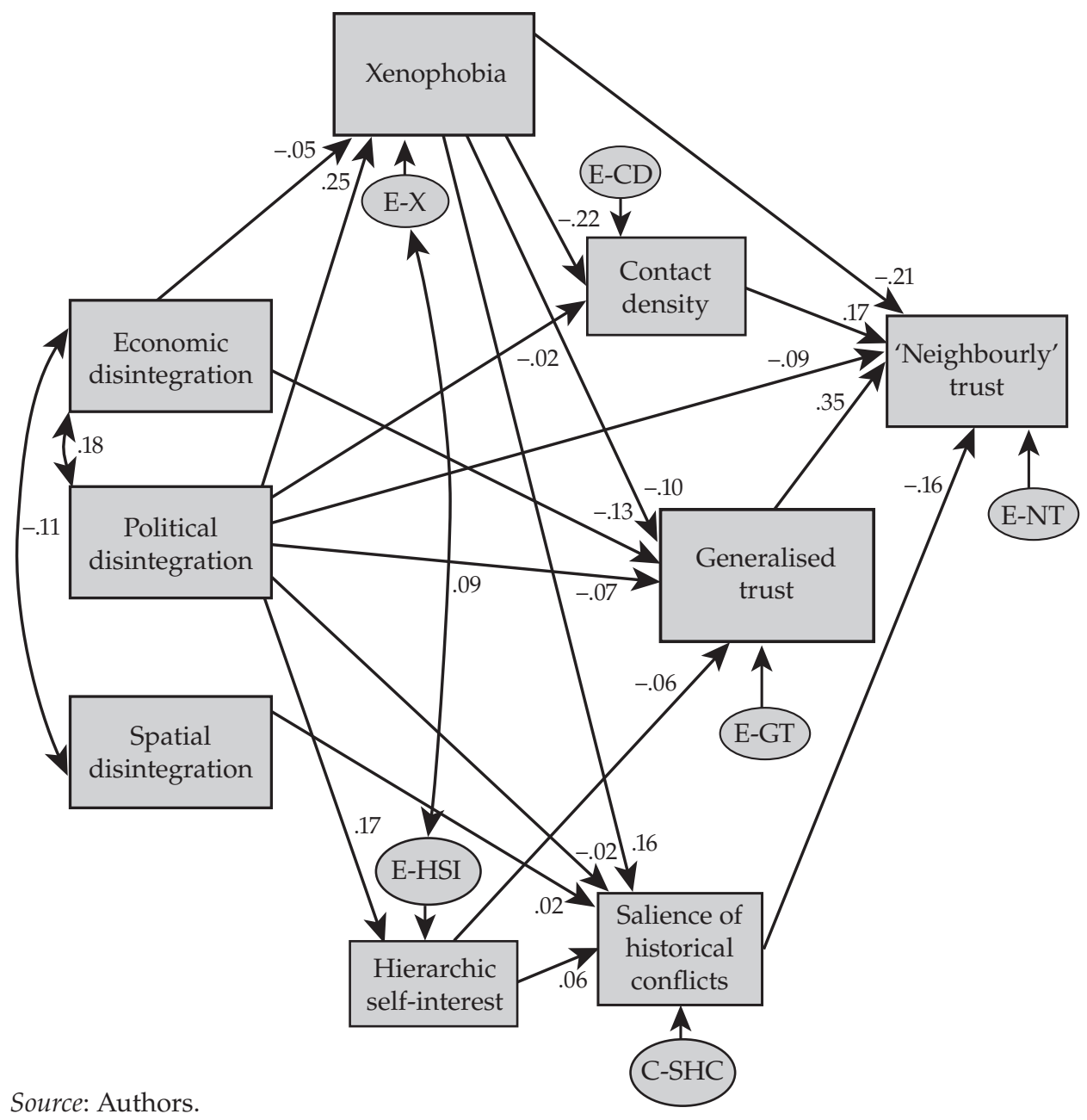

In their prediction of generalised trust, the disintegration indicators grosso modo emerged as having the effects postulated in our hypotheses. The effect sizes, however, were comparatively low. Economic disintegration resulted in a reduced level of general social trust among respondents in both the Czech and the German border region.

Similarly, political disintegration had the expected outcome, but once again with very weak though significant effect sizes: a stronger experience of political powerlessness predicted reduced general trust in both subsamples. 
Figure $1 \mathrm{~b}$. Prediction of trust in the Czech border region

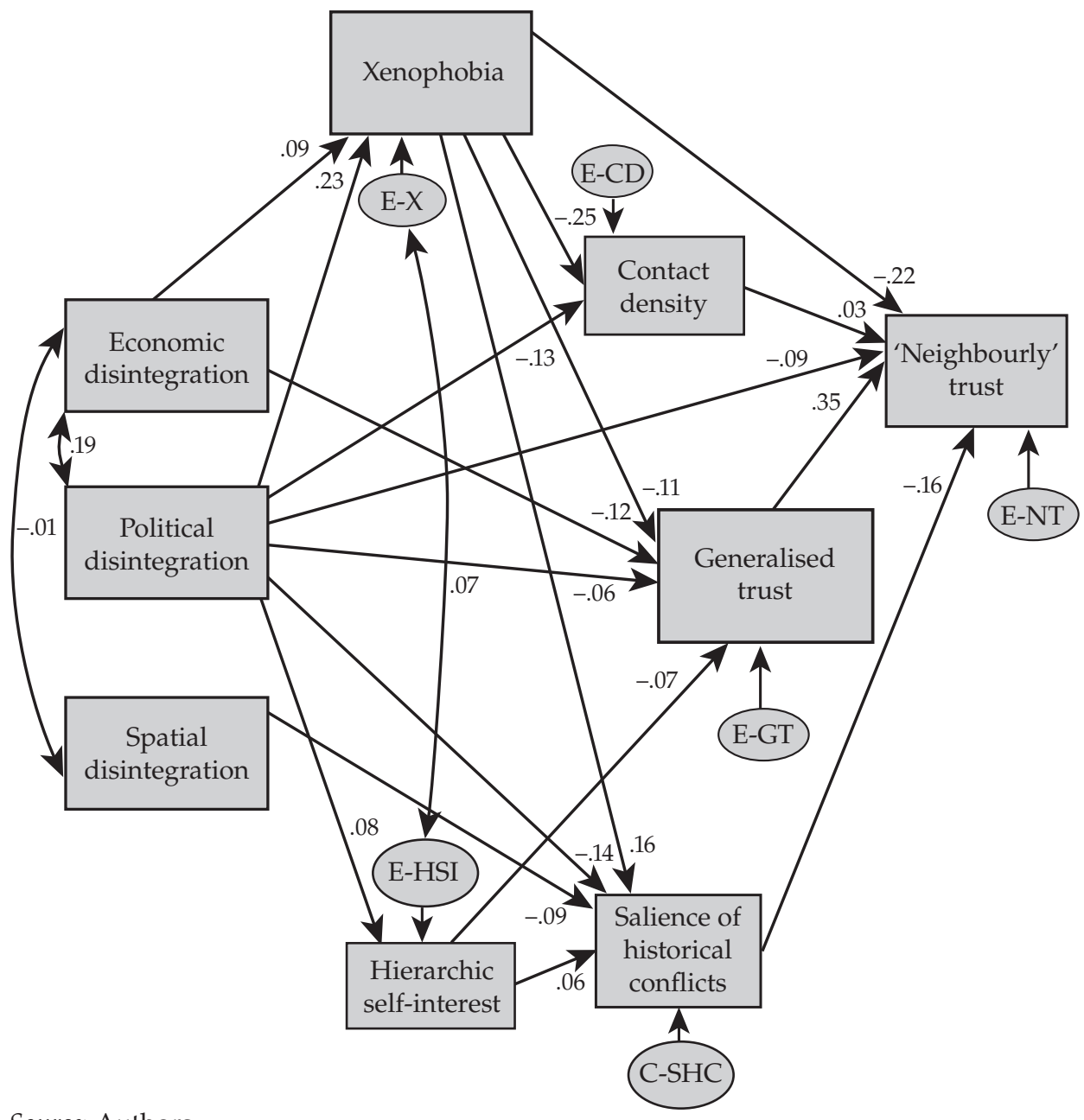

Source: Authors.

Spatial disintegration, on the contrary, did not have an impact on generalised trust. The consequences of a lack of regional rootedness obviously have to be looked at in more detail. Contrary to our expectations, mobility does not seem to be an indicator for disintegration, at least in Germany. There, having lived in the area under scrutiny only for a short time is negatively related to economic disintegration: Those who have recently moved to the area experience below-average economic disintegration. In the Czech Republic, at the same time, people who 
have moved into the area recently perceive the historical conflicts of the area as less salient.

The effects of the self-enhancement mentalities also turned out to be significant and in conformity with the hypothesised direction. In both samples, hierarchic self-interest, a syndrome of self-enhancing value orientations, sometimes called an 'elbow mentality' [Hadjar 2004] or a 'capitalist mentality' [Boehnke and Dragolov forthcoming], negatively predicted generalised trust, though once again the effect sizes were quite low. Hierarchic self-interest was itself predicted by the experience of political disintegration (more strongly so in Germany than in the Czech Republic) and thus served as a mediator of the relationship of political disintegration and generalised trust.

For xenophobia, findings were as predicted in Hypothesis $2 \mathrm{~b}$. Xenophobia significantly predicted generalised and neighbourly trust, but the impact on the latter was about twice the size of the impact on the former. Xenophobia also mediated the impact of economic and political disintegration on both types of trust; furthermore, it correlated significantly with HSI.

Hypothesis 3 assumed that the strongest predictor of neighbourly trust would be generalised trust, and this also was the empirical finding. Generalised trust alone explained more than $10 \%$ of the variance in neighbourly trust both in Germany and the Czech Republic.

Hypothesis 4 predicted that contextual variables pertaining to specificities of trans-border relations would only predict neighbourly trust but would neither predict generalised trust nor be affected by generalised trust levels. Empirical findings concurred with this assumption. There were, however, interesting cross-cultural differences in the role played by contact density and the perceived strength of the salience of historical conflicts. While hierarchically self-interested and xenophobic people tended to emphasise historical conflicts more strongly and have less contact with the trans-border 'other' in both countries, political disintegration figured differently in the two countries in the predictive network of contact and conflict. Whereas in Germany it did not predict the relational specificities of Germans and Czechs, in the Czech Republic it did: those who felt politically more powerless had less contact with Germans, but also felt historical conflicts to be less salient. As far as contact density is concerned, there was another cross-cultural difference: while for Germans increased contact predicted neighbourly trust, it did not for Czechs. For the subjectively perceived salience of historical conflicts, the findings did not differ between the two countries: stronger salience predicted lower neighbourly trust.

Table 2 summarises the predictive network of the two types of trust under scrutiny here. The table shows that generalised trust, xenophobia, and perceived political integration are the strongest predictors of neighbourly trust in Germany. Altogether $30 \%$ of the variance in neighbourly trust is explained by the eight variables in our model. In the Czech Republic the overall amount of explained variance is slightly lower $(25 \%)$. In the Czech predictive network the subjectively 
Table 2. Standardised total effects for the prediction of trust

\begin{tabular}{|c|c|c|c|c|}
\hline & \multicolumn{2}{|c|}{ Generalised trust } & \multicolumn{2}{|c|}{ 'Neighbourly' trust } \\
\hline & $\mathrm{DE}$ & $\mathrm{CZ}$ & $\mathrm{DE}$ & $\mathrm{CZ}$ \\
\hline Economic disintegration & -.13 & -.13 & -.03 & -.07 \\
\hline Political disintegration & -.10 & -.11 & -.20 & -.16 \\
\hline Spatial disintegration & - & - & .01 & .02 \\
\hline Xenophobia & -.10 & -.09 & -.31 & -.16 \\
\hline Hierarchic self-interest & -.06 & -.07 & -.03 & -.03 \\
\hline Contact density & - & - & .17 & .03 \\
\hline Salience of historical conflicts & - & - & -.16 & -.16 \\
\hline Generalised trust & & & .35 & .35 \\
\hline
\end{tabular}

Source: Authors.

— no significant effect.

perceived salience of historical conflicts played a relatively bigger role in explaining neighbourly trust (despite the fact that the $\beta$ coefficients are identical in both countries- $\beta=-.16$ ). While in Germany some $8.5 \%$ of the explained variance is accounted for by the salience rating, in the Czech Republic this variable accounts for $10.2 \%$ of the explained variance. ${ }^{10}$

For generalised trust, our findings are, once again, 'disappointing' in the sense that, as pointed out by Newton [2006], very little can be said about the individual-level precursors of generalised trust. In both countries slightly less than $5 \%$ of the variance in this variable is explained by individually perceived economic and political disintegration and self-enhancement mentalities. Of the explained variance, about two-thirds are accounted for by the two disintegration variables, the other third by the two mentality variables.

\section{Conclusion}

In sum, the search for an empirical explanation of the roots of general social trust was, in principle, successful (disintegration and self-enhancement mentalities did serve as sources of reduced trust). However, as has been the case in many other studies, effect sizes were essentially very small. The amount of variance explained in general social trust on the basis of disintegration indicators, hierarchic self-interest, and xenophobia was rather low. Heitmeyer's disintegration theory [Heitmeyer and Anhut 2008; Heitmeyer 1997], tested here for the first time in its

${ }^{10}$ Calculated as $-.16^{2} / .30(\mathrm{DE})$ as opposed to $-.16^{2} / .25(\mathrm{CZ})$. 
relation to the trust concept, is not able to account for more variance in social trust than other theories have been able to. The explanatory power of this theory matches other conceptual approaches [see Zmerli, Newton and Montero 2008; Zmerli 2008]. This is likely to be due to the multiple roots of trust. In our eyes, the at most modest impact of disintegration and of self-enhancement mentalities on trust suggests that a disposition towards general social trust develops early, for example, through relationship experiences in childhood. The lines of thinking offered by attachment theory [Cassidy and Shaver 1999] may be a better candidate for explaining trust levels in individuals than are disintegration indicators or selfenhancement mentalities. Although levels of general social trust are indeed open to change on the basis of subjective appraisals of a given societal context (here of disintegration), the 'volume' of such changes in post-childhood years appears to be limited. Specific forms of trust (here neighbourly cross-border trust) are after all more influenceable. These forms of trust, although strongly pre-formed by a person's disposition towards general trust, can be modified by cross-border contact, by media campaigns addressing historical narratives [Jaeger and Kempf 2010], and the like. Cross-national differences in the impact of contact and the subjective salience of narratives at the same time suggest that there is no catch-all approach to the generation of particular trust in border regions. One can, for example, only speculate about the reasons for the differences in the impact of contact. It could be that the general power relationship between Czechs and Germans plays a role, Germans being more powerful in economic terms than Czechs. When the powerful (the Germans) have contact with the less powerful (the Czechs), to the former the less powerful seem more trustworthy, but this does not work the other way around. For the less powerful (the Czechs) contact does not change levels of trust. But as said, this is mere speculation. Measures must be specific and will often necessarily differ on the two sides of a border.

In its attempt to link generalised trust and particular (here 'neighbourly' cross-border) trust our findings add a new twist to the recent debate on the importance of the radius of trust [Realo, Allik and Greenfield 2008; Delhey, Newton and Welzel 2011]. The report by Delhey, Newton and Welzel [2011] analysed World Values Survey (WVS) data utilising a new item battery, where trust in people from 'your neighbourhood' is a measure of ingroup trust, whereas trust in people of 'another nationality' is a measure of outgroup trust. Neighbourly, cross-border trust clearly exists in the German-Czech border region, but in the nomological network of trust it has an ambivalent position. In certain instances, cross-border neighbours virtually are neighbours in the sense of the new WVS measure. This in particular is the case since the Czech Republic became part of the EU Schengen area of open borders in 2007 (which was after data were gathered for the present study). The inhabitants of cross-border regions are now often members of the same ingroup, particularly when they live in one of the pairs of adjacent cross-border urban centres oversampled for the present study, such as Domažlice and Furth im Wald [Petrat et al. 2009]. At the same time they have 
different nationalities (and for that matter languages) and thus clearly belong to different outgroups as conceptualised in the WVS items. As the Czech Republic is not included in the most recent WVS, we can only add this twist to the puzzle, without being able to test it empirically.

KLAUS BOEHNKE is a professor of social science methodology at Jacobs University Bremen and vice dean of the Bremen International Graduate School of Social Sciences (BIGSSS). He earned his PhD from Berlin University of Technology and his habilitation from the Free University of Berlin. His research focuses on diverse topics of political socialisation and on research methodology. He is currently working on societal cohesion in a project of the Bertelsmann Foundation.

SusAnNe RIPPL, Dr. habil., is a tenured senior lecturer in the Department of Sociology of Chemnitz University of Technology, Germany. She earned her PhD at the University of Giessen, Germany. Her research focuses on youth, authoritarianism, and right-wing extremism. Her most recent projects deal with the micro-social consequences of EU enlargement in the border regions.

\section{References}

Arbuckle, James L. 2010. IBM SPSS® Amos ${ }^{\mathrm{TM}} 19$ User's Guide. Crawfordville, FL: Amos Development Corporation.

Beck, Ulrich. 1986. Risikogesellschaft. Auf dem Weg in die andere Moderne. Frankfurt/Main: Suhrkamp.

Boehnke, Klaus and Georgi Dragolov. Forthcoming. 'Social Axioms as Mediators between Culture-Level and Individual-Level Values: A Study of Sojourner Students from More Than 50 Countries.' Paper submitted for review to Cross-Cultural Research.

Cassidy, Jude and Phillip R. Shaver. 1999. Handbook of Attachment. Theory, Research and Clinical Application. New York: Guilford.

Coleman, James S. 1990. Foundations of Social Theory. Cambridge, MA: Belknap Press.

Delhey, Jan and Kenneth Newton. 2003. 'Who Trusts? The Origins of Social Trust in Seven Countries.' European Societies 5: 93-137.

Delhey, Jan and Kenneth Newton. 2005. 'Predicting Cross-National Levels of Social Trust. Global Pattern or Nordic Exceptionalism.' European Sociological Review 21: 311-327.

Delhey, Jan, Kenneth Newton and Chris Welzel. 2011. 'How General Is Trust in "Most People"? Solving the Radius of Trust Problem.' American Sociological Review 76: 786-807.

Eisenstadt, Shmuel N. 2000. 'Multiple Modernities.' Daedalus 129: 1-29.

Gabriel, Oskar W., Volker Kunz, Sigrid Rossteutscher and Jan W. van Deth. 2002. Sozialkapital und Demokratie: Zivilgesellschaftliche Ressourcen im Vergleich. Vienna: WUV Universitätsverlag.

Gambetta, Diego. 1988. Trust: Making and Breaking Social Relations. Oxford: Oxford University Press.

Giddens, Anthony. 1990. The Consequences of Modernity. Cambridge: Polity Press. 
Hadjar, Andreas. 2004. Ellenbogenmentalität und Fremdenfeindlichkeit bei JugendlichenDie Rolle des hierarchischen Selbstinteresses. Wiesbaden: Verlag für Sozialwissenschaften.

Hagan, John, Susanne Rippl, Klaus Boehnke and Hans Merkens. 1999. 'Interest in Evil: Hierarchic Self-Interest and Right-Wing Extremism among East and West German Youth.' Social Science Research 28: 162-183.

Hardin, Russell 1993. 'The Street-Level Epistemology of Trust.' Politics and Society 21: 505-529.

Harriss, John. 1992. 'The Second Great Transformation? Capitalism at the End of the Twentieth Century.' Pp. 325-342 in Poverty and Development in the 21st Century, edited by T. Allen and A. Thomas. Oxford: Oxford University Press.

Heitmeyer, Wilhelm. 1997. Was treibt die Gesellschaft auseinander? Frankfurt/Main: Suhrkamp.

Heitmeyer, Wilhelm and Reimund Anhut. 2008. 'Disintegration, Recognition, and Violence: A Theoretical Perspective.' New Directions for Youth Development 33: 25-37.

Hollis, Martin. 1998. Trust within Reason. Cambridge: Cambridge University Press.

Inglehart, Ronald. 1997. Modernization and Postmodernization. Cultural, Economic and Political Change in 43 Societies. Princeton, NJ: Princeton University Press.

Inglehart, Ronald. 1999. 'Trust, Well-Being and Democracy.' Pp. 88-120 in Democracy and Trust, edited by M. E. Warren. Cambridge: Cambridge University Press.

Inglehart, Ronald and Chris Welzel. 2005. Modernization, Cultural Change and Democracy. New York: Cambridge University Press.

Jaeger, Susanne and Wilhelm Kempf. 2010. 'Media Representations of Conflicts as Catalysts of Peace Processes.' Pp. 55-62 in Readings in Peace Journalism. FoundationsStudies-Perspectives, edited by W. Kempf. Berlin: Regener.

Knack, Stephen and Philip Keefer. 1997. ‘Does Social Capital Have an Economic Payoff? A Cross-Country Investigation.' Quarterly Journal of Economics 112: 1251-1288.

Liebhart, Ernst H. and Gerda Liebhart. 1971. 'Entwicklung einer deutschen Ethnozentrismusskala und Ansätze zu ihrer Validierung.' Zeitschrift für experimentelle und angewandte Psychologie 18: 447-471.

Luhmann, Niklas. 1988. 'Familiarity, Confidence, Trust: Problems and Alternatives.' Pp. 95-107 in Trust: Making and Breaking Cooperative Relations, edited by D. Gambetta. Oxford: Blackwell.

Macy, Michael W. and John Skvoretz. 1998. 'The Evolution of Trust and Cooperation between Strangers: A Computational Model.' American Sociological Review 63: 638-660.

Newton, Kenneth. 1999. 'Social and Political Trust in Established Democracies.' Pp. 169-187 in Critical Citizens: Global Support for Democratic Governance, edited by P. Norris. Oxford: Oxford University Press.

Newton, Kenneth. 2006. 'Social and Political Trust.' Pp. 342-361 in The Oxford Handbook of Political Behavior, edited by R. J. Dalton and H. D. Klingemann. Oxford: Oxford University Press.

Niebuhr, Annekatrin. 2008. 'The Impact of EU Enlargement on European Border Regions.' International Journal of Public Policy 3: 163-186.

Paxton, Pamela. 2002. 'Social Capital and Democracy-An Interdependent Relationship.' American Sociological Review 67: 254-277.

Petrat, Anke, Angela Kindervater, Susanne Rippl and Klaus Boehnke. 2009. Transnationale Zivilgesellschaft. Einsichten und Perspektiven aus Städten in Grenzregionen. Frankfurt am Main: Lang.

Portes, Alejandro. 1998. 'Social Capital: Its Origins and Applications in Contemporary Sociology.' Annual Review of Sociology 24: 1-24.

Putnam, Robert D. 1993. Making Democracy Work-Civic Traditions in Modern Italy. Princeton, NJ: Princeton University Press. 
Putnam, Robert D. 1995. 'Bowling Alone: America's Declining Social Capital.' Journal of Democracy 6: 65-78.

Putnam, Robert D. 2000. Bowling Alone: The Collapse and Revival of American Community. New York: Simon \& Schuster.

Realo, Anu, Jüri Allik and Brenna Greenfield. 2008. 'Radius of Trust-Social Capital in Relation to Familism and Institutional Collectivism.' Journal of Cross-Cultural Psychology 39: 447-462.

Rippl, Susanne, Nicola Bücker, Anke Petrat and Klaus Boehnke. 2010. 'Crossing the Frontier. Transnational Social Integration in the EU's Border Regions.' International Journal of Comparative Sociology 51: 5-31.

Schiefer, David, Anna Möllering, Ella Daniel, Maja Benish-Wiseman and Klaus Boehnke. 2010. 'Cultural Values and Outgroup Negativity: A Cross-Cultural Analysis of Early and Late Adolescents.' European Journal of Social Psychology 40: 635-651.

Schwinn, Thomas (ed.). 2006. 'Die Vielfalt und die Einheit der Moderne. Kultur- und strukturvergleichende Analysen.' Wiesbaden: VS Verlag für Sozialwissenschaften.

Simmel, Georg. (1902) 1992. Soziologie: Untersuchungen über die Formen der Vergesellschaftung. Frankfurt: Suhrkamp.

Tönnies, Ferdinand. (1887) 2005. Gemeinschaft und Gesellschaft. Grundbegriffe der reinen Soziologie. Darmstadt: Wissenschaftliche Buchgesellschaft.

Uslaner, Eric M. 2002. The Moral Foundations of Trust. New York: Cambridge University Press.

Whiteley, Paul F. 1999. 'The Origins of Social Capital.' Pp. 25-44 in Social Capital and European Democracy, edited by J. W. van Deth. London: Routledge.

Zmerli, Sonja. 2008. Inklusives und exklusives Sozialkapital in Deutschland. Grundlagen, Erscheinungsformen und Erklärungspotential eines alternativen theoretischen Konzepts. Baden-Baden: Nomos.

Zmerli, Sonja, Kenneth Newton and José R. Montero. 2008. 'Trust in People, Confidence in Political Institutions, and Satisfaction with Democracy.' Pp. 35-65 in Citizenship and Involvement among the Populations of European Democracies. A Comparative Analysis, edited by J. W. van Deth, J. R. Montero and A. Westholm. London: Routledge. 